\title{
ULTRASTRUCTURAL STUDY ON THE EFFECT OF A PLANT MOLLUSCICIDE (SOLANUM ELAEAGNIFOLIUM) ON THE DIGESTIVE AND HERMAPHRODITE GLANDS OF BIOMPHALARIA ALEXANDRINA
}

\section{Abdalla M. Ibrahim ", Wafaa L. F. Ibrahim ${ }^{2}$ and Noran A. H. Abou-Aouf ${ }^{2}$}

1-Zoology Department, Faculty of Science, Ain Shams University. 2-Zoology Department, Faculty of Science (for girls), Al-Azhar University.

Key words: Ultrastructure, Solanum, digestive gland, hermaphrodite gland, Biomphalaria alexandrina.

\section{ABSTRACT}

Tltrastructure examination was applied to study the effect of short (4 days) and long (10 days) exposures to sublethal concentration (1 ppm) of ethanol extract of Solanum elaeagnifolium seeds (S. elaeag.) (Family: Solanecae) on the digestive gland and hermaphrodite gland of infected and uninfected the pulmonate snail Biomphalaria alexandrina.

Ultrastructural studies of the above two glands of infected snails illustrated remarkable cytological changes due to the infection with marked increase in the cytoplasmic vacuolation that almost occupied the whole cell of the digestive gland.

The ultrastructural changes in the digestive and hermaphrodite gland cells due to exposure of snails to ethanol extract of the candidate plant showed degeneration in the nucleus, nucleolus and mitochondria with abnormal Golgi complex as well as in glycogen digestion.

\section{INTRODUCTION}

Schistosomiasis is one of the serious parasitic diseases which attack. many people in tropical and subtropical regions of the world causing serious losses in health and economy. In Egypt, the disease stands on the top of the public health problems and its impact on the health and economy is tremendous. Thus a considerable attention has been focused on its control by various means of which the control of the intermediate host snails of the parasite seems to be most possible if properly handled. 
Abdalla M. Ibrahim et al.

Biomphalaria alexandrina ( Ehrenberg) is known to be the pulmonate species that acts as the intermediate host of Schistosoma mansoni in Egypt.

The high cost and toxicity of synthetic molluscicides, used for the control of intermediate snail hosts of parasitic diseases, resulted in renewing the interest in plant molluscicides (Massoud and Habib,2003).

The screening of local plants for their molluscicidal activity has received increasing attention by many authors (Tantawy et al., 2000; Bakry et al., 2002).

Extracts of plants in the genus Solanum (Solanaceae) showed significant mulluscicidal activity against some planorbid snails, (Bekkouch et al., 2000; Silva et al.,2005).

Some general studies do exist about the ultrastructure of the digestive gland of certain molluscs, the most comprehensive of which were published by Walker(1970) and Pol(1971).

On the electron microscopic level, Meuleman(1972) elucidated the changes induced in the digestive gland of south African strains of $B$. pfefferi as a result of infection with Schistosoma mansoni.

Chen $e$ al. (2004) studied the ultrastructural changes induced in the hepatopancreas of the gastropod Haliotis diversicolor as a result of ulcerate disease. The ultrastructural effects of extracts from Tetrapleura tetraptera (Taub.) and Bayluside on the digestive gland of B. glabrata were investigated by Bode et al. (1996). The hepatopancreas and reproductive system in normal Oncomelania hupensis snails and in snails after treatment with seed extracts of Camellia sinensis were ultrastructurally examined by Song et al. (1997).

The present work aimed to study the effect of $S$. elaeagnifolium on infected and uninfected $B$. alexandrina as indicated by its action on the fine structure of both digestive and hermaphrodite glands.

\section{MATERIALS AND METHODS}

Solanum elaeagnifolium (Cav.) (Family: Solanaceae) was collected from north east Sainai, near El-Arish city. 250 grams of unripe seeds of Solanum elaeagnifolium were exhaustively extracted with $9.5 \%$ ethanol at rocin : mperature. The extract was evaporated to dryness under vacuum. From the crude extract, a stock solution was prepared.

B. alexandrina snails (noninfected and infected with $S$. mansoni) were obtained from Theodor Bilharz Research Institute, Imbaba, Giza, Egypt. 
Experimental design:Infected (shedding cercaria) and uninfected $B$. alexandrina snails(5-6 weeks old) were treated with subiethil concentration (1ppm) of ethanol extract of Solanum elaeagnifolium. Som. of them were exposed to molluscicidal solution for 4 days and then recovered for 1 week. Others were exposed for 10 days continuously to the molluscicide.

Snails were then dissected to obtain the digestive and hermaphrodite glands to be prepared for ultrathin section examinations.

Experimental conditions: During the experiments, snails were maintained at constant conditions of temperature $\left(26^{\circ} \mathrm{c} \pm 2^{\circ} \mathrm{c}\right)$ and artificial illumination ( 11 hours/day).

Electron microscopy: $1 \mathrm{~mm}$ of both the digestive gland and the hermaphrodite gland of both infected and uninfected snails were primary fixed in $2 \%$ gluteraldehyde in sodium cacodylate buffer $(0.1 \mu, \mathrm{PH} 7.4)$ for two hours at $4^{\circ} \mathrm{c}$ and then post fixed in $1 \%$ buffer osmium tetroxide for two hours at $4^{\circ} \mathrm{c}$. The samples were dehydrated in acetone and embedded for 12 hours in Epon resin (812) (Luft, 1961). Ultrathin sections were cut and then mounted on copper grids, stained with uranyle acetate and lead citrate, and examined with Jeal JEM $100 \mathrm{~S}$ transmission electron microscope.

\section{The digestive gland:}

\section{RESULTS}

The digestive gland of Biomphalaria alexandrina consists of two main types of cells, the digestive and secretory cells.

The digestive cells:

The electron microscope examination of uninfected and infected snails has revealed the presence of long, dense microvilli along the apical areas of the plasma membranes of the digestive cells (Fig. 1). It also shows scattered cilia along the luminal surface of these cells, each containing an axial filament complex of the conventional $9+2$ configuration. The microvilli, as the cilia, are bounded by apical extensions from the plasma membranes of the cells.

The ground cytoplasm of such cells contains a granular endoplasmic reticulum, mitochondria and occasionally Golgi complex. Also the digestive cells possess numerous digestive vacuoles of variable size (Fig. 1). The nuclei of the digestive cells occupy the basal regions, each containing a conspicuous nucleolus.

The secretory cells: 
In the secretory cells of the digestive gland, the nucleus is situated in the broad basal part of the cell. At the ultrastructural level, the nucleolus appears to consist of a dense central part, surrounded by a less compact outer zone. The chromatin occurs mainly as clumps which lie scattered through the nucleoplasm and against the nuclear envelope. Outgrowths of the outer membrane of the nuclear envelope are continuous with cisternae of granular endoplasmic reticulum (GER). The extensive GER which is composed of tubules and numerous, mainly parallel, cisternae accounts for the strong basophilia of the cytoplasm, while a well develop Golgi apparatus is located in the supranuclear region. Mitochondria often occur in close association with the secretion granules (Fig. 2). A high density of mitochondria, longer and thicker than those of the digestive cells and occasionally containing small electron-dense granules are found apical to the nucleus and over the basal cell membrane.

The degeneration of the secretory cells starts with the appearance of few vacuoles containing yellow bodies in the cytoplasm. Their ultrastructural examination show that these vacuoles contain acid phosphatase and so are probably autophagosomes and recognized as degenerating cell organelles.

- The digestive cells of infected snails displayed various signs of degeneration. The endoplasmic reticulum became distinctly swollen and the mitochondria were reduced in number, more elongated and accumulated (Fig.3). The cytoplasmic vacuoles became abundant without any apparent inclusions, causing change in the nucleus shape, the secretory cells of digestive gland displayed numerous vacuoles also (Figs.4\&5).

Ultrastructural changes of digestive gland after treatment with $1 \mathrm{ppm}$ ethanol extract of $S$. elaeagnifolium for 4 days and recovery for 1 week, showed phosphohydrolase reactions producing an accumulation of dense stain precipitate, surrounding the nucleus which started to separate from the cytoplasm presenting a narrow suture (Fig. 6). However, the chromatin clumps were decreased. and scattered against the nuclear envelope. This is probably an autophagosome indicating a sign of cell organelles degeneration.

No more damage in the digestive gland cell content was observed after short exposure to the molluscicide except a high density of mitochondria which appeared cloudy because the density of the matrix decreased and the inner membrane became displaced and collapsed onto 
a limited area of the external membrane. Some of these mitochondria appeared swollen.

At daughter sporocyst, the mitochondria revealed more damage ano part of them became degenerated and seemed vacuolated mitochondria (Fig. 7).

The same pathogenesis was observed in the digestive gland of snails exposed to $1 \mathrm{ppm}$ ethanol extract of $S$. elaeagnifolium for 10 days (Fig.8). However, more degeneration occurred in the endoplasmic reticulum accompanied with neumerous vacuoles.

The hermaphrodite gland:

Under light microscope, the sperm of $B$. alexandrina appears as an extremely long thin filament with a slightly enlarged anterior tip. At higher magnifications, a small corkscrew-shaped head is discernible ; provided with an acrosome and followed by a helicoidal middle piece which ends in a short tail (Fig. 9). The helix of the middle piece appears double in most of its length but is single near the tail.

The inner organization of the sperm components was better understood by the ultrathin section examination (Fig. 10). Oogonia and mature ova are relatively little and therefore rarely seen.

The hermaphrodite gland appeared more affected than the digestive gland, especially in snails exposed to $1 \mathrm{ppm}$ of ethanol extract of $S$. elaeagnifolium for 10 days. After short exposure period (4 days) and 1 week recovery to $1 \mathrm{ppm}$ of the plant molluscicide, the plasma membrane of the sperms appeared as dense fibrous bands (Fig. 11). Glycogen granules in the normal sperms appear as dense granules within the mitochondrial derivative, but after short exposure ( 4 days) and recovery for 1 week, they appeared as very fine granules.

Prolonged exposure to the molluscicide (for 10 days) had caused glycogen digestion (Fig. 12). Enzymatic digestion of different parts of the axial complex and microtubules were also noticed with atrophied sperm tails (Fig. 13).

In secondary spermatocytes, the mitochondria showed severe damage (Figs. $14 \& 15$ ). They became accumulated, swollen with active long cristae, although most of them were degenerated and some appeared vacuolated. Swelling may be due to toxins that act presumably by alternating to osmotic pressure within the cells, thereby causing inhibition of water. Some of the nuclear elements started to degenerate, such as the nuclear envelope, nucleolus and chromatin contents (Fig.14). On the other 
hand, vacuoles were evident in the secondary spermatocytes due to the cytoplasmic digestion (Fig. 15).

\section{DISCUSSION}

Plant molluscicides are gaining increased attention as they may be highly effective, rapidly biodegradable, less expensive than synthetic molluscicides, readily available and probably easily applicable with simple techniques. Therefore, they are appropriate for snail control measures against schistosomiasis in endemic areas (Marston and Hostettmann, 1985). They also can play an important role in developing countries suffering from the exceeding cost of importing synthetic molluscicides with scarce hard currency (Mc Cullough et al., 1980).

The digestive gland of the snail $B$. alexandrina is mainly composed of two cell types, digestive and secretory ones as had also been elucidated by Meuleman (1972) and Lutfy et al. (1973), in their studies on Biomphalaria pfeifferi and Bulinus truncatus respectively.

The present ultrastructural observations revealed that the apical portions of the plasma membranes in the digestive cells of the uninfected snails are extended into numerous microvilli. This confirms the results of Meuleman (1972) and Reader (1976) on the digesiye glands of Biomphalaria pfeifferi and Bithynia tentaculate respectively. However, the microvilli had almost disappeared from digestive cells of the infected snails (Mohamed and Saad, 1990).

The vacuolation observed in the digestive gland cells of $B$. alexandrina are believed to be closely related to the digestive and absorptive processes going on in these cells. This confirms the results postulated by Summer (1968) on Helix. Saad and Mohamed (1989) on Bulinus truncatus and Mohamed and Saad (1990) on B. alexandrina. However, such vacuoles were presumably produced as a result of the coalescence of the pinocytotic vesicle which develop along the apical portions of the plasma membranes adjacent to the tubular lumen.

Moreover, the digestive cells of uninfected snails possess numerous relatively small vacuoles. However, snails infected with $S$. mansoni showed a marked increase in the cytoplasmic vacuolation to the extent that they almost occupied the whole cells. This observation agrees with that of Reader (1976) presented in such cases. Furthermore, increased vacuolation in the digestive gland cells of infected snails is a remarkable phenomenon associated with infection (Moore and Halton, 1973). According to the latter authors, cytoplasmic vacuolation is actively 
correlated with the release of hydrolytic enzymes which impose several changes in the intracellular system of infected snail (Saad and Mchmad, 1989).

The present observations indicate the breakdown of digestive gland of Biomphalaria snails due to the presence of the parasite $S$. mansoni. Such tissue damage provides the foundation for the observed mortality associated with effects of this parasite on the snail.

Wang et al. (1991) noted that the ultrastructure of hepatopancreas cells are markedly influenced by bromoacetamide, including swelling of mitochondria and splitting of cristae. This finding correlates with a decrease in action of enzymes located in mitochondria ( ornithine carbamyl-transferase, citric acid synthease).

The results obtained by Chen et al. (2004) revealed that when ulcerate disease occurred in the gastropod Haliotis diversicolor, uitrastructural changes in hepatopancreas cells appeared (swelling, denaturation and necrosis).

Electron microscopy of $B$. alexandrina sperm reveals clearly several of its anatomical details. Most of these features are similar to the descriptions made from sperms of some other pulmonate gastropods (Anderson and Personne, 1970a\&b ; Hachiri and Higashi, 1972) but nevertheless some peculiarities exist. There is a general agreement with previous electron microscopical descriptions of $B$. glabrata sperm by Bogitsh (1974a\&b), Kitajima and Paraense (1976) and Brackenbury and Appleton (1991).

Glycogen granules, identified as such by cytochemical technique, were present within the mitochondria derivatives, intraxonemally, and surrounding the axial complex at the tail region. This observation is in line with previous descriptions in other gastropods. Bogitsh (1974a\&b) also identified cytochemicaily the glycogen nature of the dense granules within the mitochondrial derivative of $B$. glabrata sperm, but apparently he did not detect them within the axoneme, nor the paracrystalline sheath of the mitochondrial derivative, suggesting that the sperms noted by Bogitsh were not fully mature. As pointed out by Anderson and Personne $(1970 \mathrm{a} \& \mathrm{~b})$, this polysaccharide storage should undoubtedly serve as an endogenous source of energy, permitting a long period of viability for the sperm.

Ultrastructure examinations was done in the present investigation to point the cytological changes in both the digestive and hermaphrodite glands in $B$. alexandrina treated with ethanol extract of $S$. elaeagnifolium 
Abdalla M. Ibrahim et al.

$1 \mathrm{ppm}$ (for 4 days and recovery for 1 week and for long exposure of 10 days). The results revealed no severe changes in cell biology after the short exposure and recovery. However, long exposure caused severe cell damage, degeneration in the nucleus and mitochondria, abnormal Golgi complex, spermatides and 'spermatozoa, associated with detected glycogen digestion.

Kitajima and Paraense (1976) obtained similar results of glycogen digestion of $B$. glabrata spermatozoa treated with amylase. More recently, Song et al. (1997) found that the exposure of the snail, Oncomelania hupensis to seed extract of Camellia sinensis (8 micro $\mathrm{g} / \mathrm{ml}$ ) for 24 hours induced a swelling and necrosis of hepatopancreas, coagulation and dissolution of spermatogonia, swelling of spermatid membrane and aggregation of mitochondria.

Therefore, the present results indicate that ethanol extract of $S$. elaeagnifolium is an effective molluscicide against $B$ alexandrina and thus can be used for schistosomiasis control in the local environment.

\section{REFERENCES}

Anderson, W.A. and Personne, P. (1970 a). Recent cytochemical studies on spermatozoa of some invertebrate and vertebrate sperm. In Baccetti, B., ed., comparative spermatology, Accademia Nazionale dei Lincei, Rome,pp 431-449.

Anderson, W.A. and Personne, P. (1970 b). The localization of glycogen in the spermatozoa of various invertebrate and vertebrate species. J. Cell Biol., 44: 29-51.

Bakry, F.A.; Ragab, F.M.A. and Sakran, A.M.A. (2002).Effect of some plant extracts with molluscicidal properties on some biological parameters of Biomphalaria alexandrina snails. J. Ger. Soc. Zool., 16: $101-111$.

Bekkouche, K.; Markouk, M.; Larhsini, M.; Jana, M. and Lazrek, H.B. (2000). Molluscicidal properties of glycoalkaloid extracts from Moroccan Solanum species. Phytother. Res., 14(5): 366-367.

Bode, A.U.; Adewunmi, C.O.; Dorfler, G. and Becker, W. (1996). the effects of extracts from Tetrapleura tetraptera (Taub.) and 
Bayluscide on cells and tissue structures of Biomphalaria glabrata (Say). J. Ethnopharmacol., 50(2): 103-113.

Bogitsh, B.J. (1974 a). Cytochemical observations on the mid-piece of the spermatozoa of the gastropod Biomphalaria glabrata. Trans. Amer. Micros. Soc., 93: 211-219.

Bogitsh, B.J. (1974 b). Acid phosphatase activity in spermatids of the snail Biomphalaria glabrata. Trans. Amer. Micros. Sco., 39: 365373.

Brackenbury, T.D. and Appleton, C.C. (1991). Morphology of the mature spermatozoon of Bulinus tropicus (Gastropoda: Planorbidae). Malacolo., 33(1-2): 273-280.

Chen, Z.; Lu, J.Y. and Wu, J.Y. (2004). Pathological studies on ulcerate disease in Haliotis diversicolor: Chinese J. Zool., 39: 6-9.

Hachiri, S. and Higashi, S. (1972). Utilization of glycogen in spermatozoa of pond snails, Sinotaria histrica and Heterogen longispira. Mem. Fac. Educ. Shiga Univ. Nat. Sci., 22: 43-57.

Kitajima, E.W. and Paraense, W.L. (1976). The ultrastructure of mature sperms of the freshwater snail Biomphalaria glabrata (Mollusca, Gastropoda). Trans. Amer. Micros. Soc., 95(1): 1-10.

Luft, J. (1961). Improvement in epoxy resin embedding method. J. Biophys. Biochem. Cytol., 9: 409-414.

Lutfy, R.C.; Demian, E.S. and Haron, N.H. (1973). the histology of the hermaphrodite gland of Bulinus truncatus (Audouin). Bull. Zool. Soc. Egypt., 25: 55-62.

Marston, A. and Hostettmann, K. (1985). Plant molluscicides. Phytochem., 24(4): 639-652.

Massoud, A.M. and Habib, F.S.M. (2003). The effect of Myrrh Commiphora molmol on the infected snails of Schistosoma sp. And their egg masses: Effect on shedding of cercariae and on snail fecundity. J. Egypt. Soc. Parasitol., 33(2): 585-596. 
Mc Cullough, F.S.; Gayral, P.; Duncan, J. and Christie, J. (1980). Molluscicides in schistosomiasis control. Bull. Wld. Hlth. Org., 58(5): 681-689.

Meuleman, E.A. (1972). Host parasite interrelationships between the freshwater pulmonate Biomphalaria pfeifferi and the trematode Schistosoma mansoni. Neth. J. Zool., 22(4): 355-427.

Mohamed, S.H. and Saad, A. (1990). Ultrastructure studies on the digestive gland of Biomphalaria alexandrina infected with Echinostoma liei. Egypt. J. Appl. Sci., 5(8): 72-80.

Moore, M.N. and Halton, D.W. (1973). Histochemical changes in the digestive gland of Lymnaea truncatula infected with Fasciola hepatica. Z. Parasitenked., 43(1): 1-16.

Pol, S.G. (1971). The fine structure of the digestive tubules of $M y a$ arenaria L. 1. Basophil cell. Proc. Malac. Soc. London, 39: 303309.

Reader, T.A.J. (1976). Studies on the ultrastructure, histochemistry of the uninfected digestive gland of Bithynia tentaculata (Mollusca: Gastropoda) and on the ultrastructure of this host organ in snails infected with larval digeneans. Z. Parasitenked., 50: 11-30.

Saad, A. and Mohamed, S.H. (1989). Histological and histochemical studies on the digestive gland of Bulinus truncatus infected with Schistosoma haematobitum. J. Egypt. Soc. Parasitol., 19(2): 617627.

Silva, T.M.; Batista, M.M.; Camara, C.A. and Agra, M.F. (2005). Moliuscicidal activity of some Brazilian Solanum sp. (Solanaceae) against Biomphalaria glabrata. Ann. Trop. Parasitol., 99(4): 419425.

Song, G.M.; Wang, G.F.; Ma, J. and Yang, J.Y. (1997). Effect of seed of Camellia sinensis on the hepatopancreas and genital system of Oncomelania hupensis. Chinese J. Parasitol. and Parasitic Diseases, $15(3)$ : 170-173. 
Summer, A.T. (1968).Experiments on phagocytosis and lipid absorption in the alimentary system of Helix. J. Roy. Microsc. Soc., 84: 415421.

Tantawy, A.; Sharaf El-Din, A.T. and Bakry, F.A. (2000). Laboratory evaluation of the mollusciciding activity of Solanum dubium (Solanaceae) against Biomphalaria alexandrina snails. J. $1^{\text {st }}$ Inter. Cong. Biol. Sci. (ICBS), Tanta University, I(2): 307-318.

Walker, G. (1970). The cytology, histochemistry and ultrastructure of the cell types found in the digestive gland of the slug, Agriolimax reticulates (Muller). Protopla., 71(1-2): 91-109.

Wang, G.F.; Song, G.M. and Becker, W. (1991). Mode of action of the molluscicide bromoacetamide. Comp. Biochem. Physiol. Pharmacol. Toxicol., 100(3): 373-379. 


\section{LEGEND OF FIGURES}

Fig.1:Ultramicrograph of digestige cells of the digestive gland of uninfected Biomphalaria alexandrina showing lipid droplets (L), mitochondria (M), microvilli (mv), cilia (ci), nucleus $(N)$ and digestive vacuoles (V). X 10000.

Fig. 2:Ultramicrograph of secretory cells of the digestive gland of uninfected $B$. alexandrina showing nucleus $(N)$ with clumps of chromatin (cr), endoplasmic reticulum (GER), mitochondria (M) and vacuoles (V). X 6000.

Fig. 3:Ultramicrograph of digestive cells of the digestive gland of infected $B$. alexandrina showing mitochondria (M), endoplasmic reticulum (GER) and vacuoles (V). X 20000.

Fig. 4:Ultramicrograph of secretory cells of the digestive gland of infected $B$. alexandrina showing the accumulation of mitochondria (arrow), secretory granules (Sc.g), vacuoles (V), degeneration in cytoplasm (D). Note the amoeboid shape of the nucleus (N) as a result of the spongy tissue. $\mathrm{X} 6000$.

Fig. 5:Ultramicrograph of secretory cells of the digestive gland of infected $B$. alexandrina showing secretory granules (Sc.g). Note the degeneration of cytoplasm content (D), endoplasmic reticulum (ER) and nucleus (N) with large nucleolus (no). X 5000 .

Fig. 6:Electron micrograph of portion of the digestive gland of $B$. alexandrina treated with ethanol extract of $S$. elaeagnifolium for 4 days and recovery for 1 week showing accumulation of phosphohydrolase enzyme (curved arrow) and (double head arrow). Note the suture (single arrow) between the nucleus $(N)$ and the cytoplasm. Note also that the chromatin clumps (Cr) decreased, presence of glycogen $(\mathrm{g})$, vacuoles $(\mathrm{V})$, mitochondria $(\mathrm{M})$, lipids (L) and microvilli (mv). X 6000.

Fig. 7:Ultramicrograph of part of a section of the digestive gland of $B$. alexandrina exposed to ethanol extract of $S$. elaeagnifolium for 4 days and recovery. for 1 week showing daughter sporocyst enveloped by the tegument ( $\mathrm{T}$ ) surrounding the germinal cells (GC) which contains large nucleus (N) with 
dispersed chromatin granules and nucleolus (no). Note that the surface of the tegument has spiny microvilli (S) which is different from the snail tissue microvilli (mv). The daughter sporocyst had vacuolated mitochondria (M). X 5000 .

Fig. 8: Electron micrograph of portion of digestive gland of $B$. alexandrina exposed to ethanol extract of $S$. elaeagnifolium for 10 days showing degeneration (D) in endoplasmic reticulum (ER). The gland is rich with lipids $(\mathrm{L})$ and vacuoles $(\mathrm{V})$. Note, vacuolated mitochondria (M) and Golgi complex (Gi). X 6000 .

Fig. 9:Photomicrograph of normal $B$. alexandrina sperm appears as an extremely long thin filament with a slightly enlarged anterior tip showing a small corkscrew-shaped head. The sperm s dense stain indicating the presence of rich polysaccharide. Note the helicoidal shape (spots) in the sperm's tail (arrow). (Gomori) X 1000.

Fig. 10:Ultramicrograph of hermaphrodite gland of normal $B$. alexandrina showing transverse sections of different regions of spermatozoa tails. MP, midpiece region with double glycogen helix (thick arrows) and single glycogen helix (small arrows). MD, mitochondrial derivative region indicated by the absence of glycogen helices. En, end piece region, rich with glycogen. Note the longitudinal sections. $\mathrm{X} 8000$.

Inset A:Transverse section through single helix glycogen region of midpiece of mature spermatozoon of normal B. alexandrina. $\mathrm{X}$ 10000.

Inset B:Transverse section through double helix glycogen region of midpiece of mature spermatozoon of normal $B$. alexandrina. $\mathrm{X}$ 10000 .

Inset C:Transverse section of head of spermatozoon of $B$. 'alexandrina showing the groove (arrow) between the acrosome and head compact nucleus. Note the electron transparent patches. X 10000 .

Inset D:Transverse section through the neck region (NK) and midpiece region (MP) of $B$. alexandrina spermatozoon. $A X$, axoneme; $C F$, coarse fibers; $g$, glycogen; $N$, nucleus. $X 8000$. 
Fig. 11:Ultramicrograph of hermaphrodite gland of $B$. alexandrina treated with $1 \mathrm{ppm}$ of $S$. elaeagnifolium for 4 days and recovery for 1 week, showing longitudinal sections of double helix glycogen region. Note that the glycogen $(\mathrm{g})$ slightly affected and the plasma membrane (PM) looks as dense fibrous bands ruptured in some locations (arrows). X8000.

Fig. 12:Ultramicrograph of hermaphrodite gland of $B$. alexandrinaa treated with ethanol extract of $S$. elaeagnifolium for 10 days showing sperm sections. Glycogen like granules were digested from the deposits in the middle piece (MP) and the end piece (En) leaving empty spaces (arrows). Note the axoneme (Ax) and mitochondrial derivative (MD), one of the sperm was cut longitudinally to its length at the middle piece and exhibits the regular periodicity of the paracrystalline sheath of mitochondrial derivative and glycogen helix. X 8000 .

Fig. 13:Ultramicrograph through different regions of middle piece (upper region) of spermatozoon of $B$. alexandrinaa treated with ethanol extract of $S$. elaeagnifolium for 10 days showing longitudinal sections with ingested glycogen helices (arrows). Note the paracrystalline materials (PC), axial complex (Ax), mitochondrial derivative $(\mathrm{MD})$ and degeneration $(\mathrm{D})$ of plasma membrane and paracrystalline material. X6000.

Fig. 14:Ultramicrograph of hermaphrodite gland of $B$. alexandrina treated with ethanol extract of $S$. elaeagnifolium for 10 days showing transverse section of secondary spermatocytes with large nuclei $(\mathbb{N})$ and distinct nucleoli (no). Note the accumulation, degeneration and swollen of mitochondria ( $(\mathrm{M})$, degeneration at nuclear membrane (single arrows), degeneration at nucleolus (double arrows) and nucleus chromatin (D). X 8000 .

Fig. 15:Ultramicrograph of spermatocytes of B. alexandrina treated with ethanol extract of $S$. elaeagnifolium for 10 days showing complete degeneration at nuclear membrane (arrows), degeneration of cytoplasmic content and mitochondria (D). Note abnormal Golgi complex (Gi) and active cristae of mitochondria (C). X 10000. 

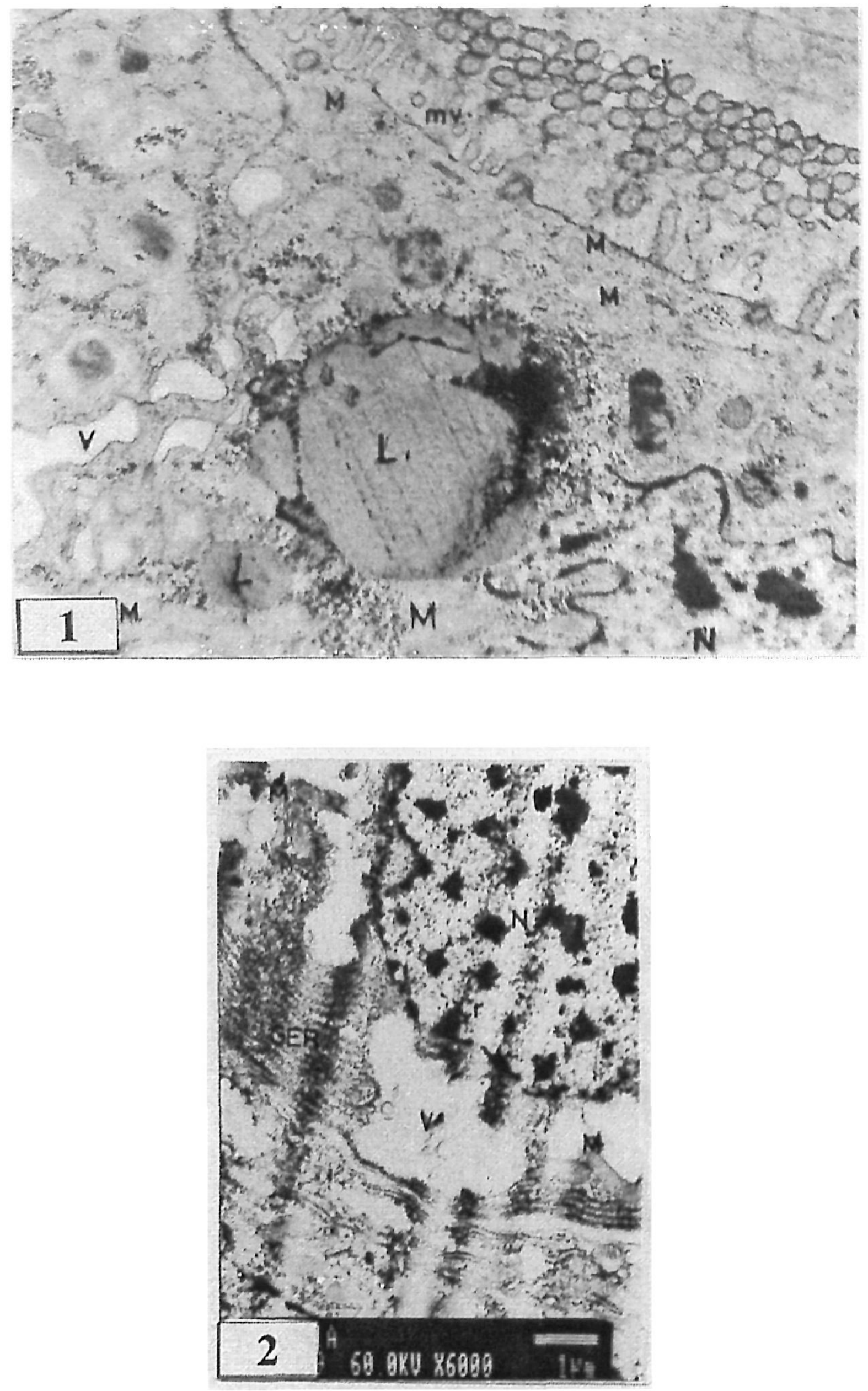

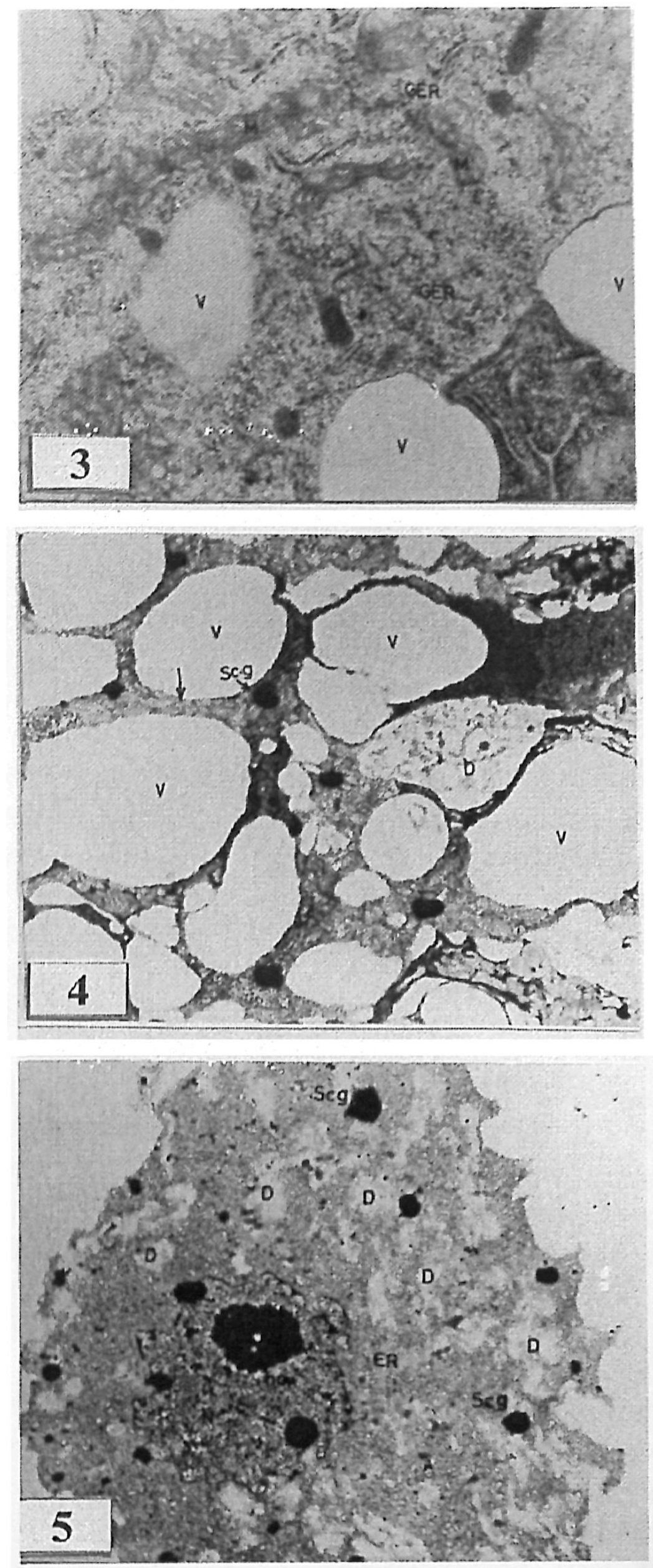

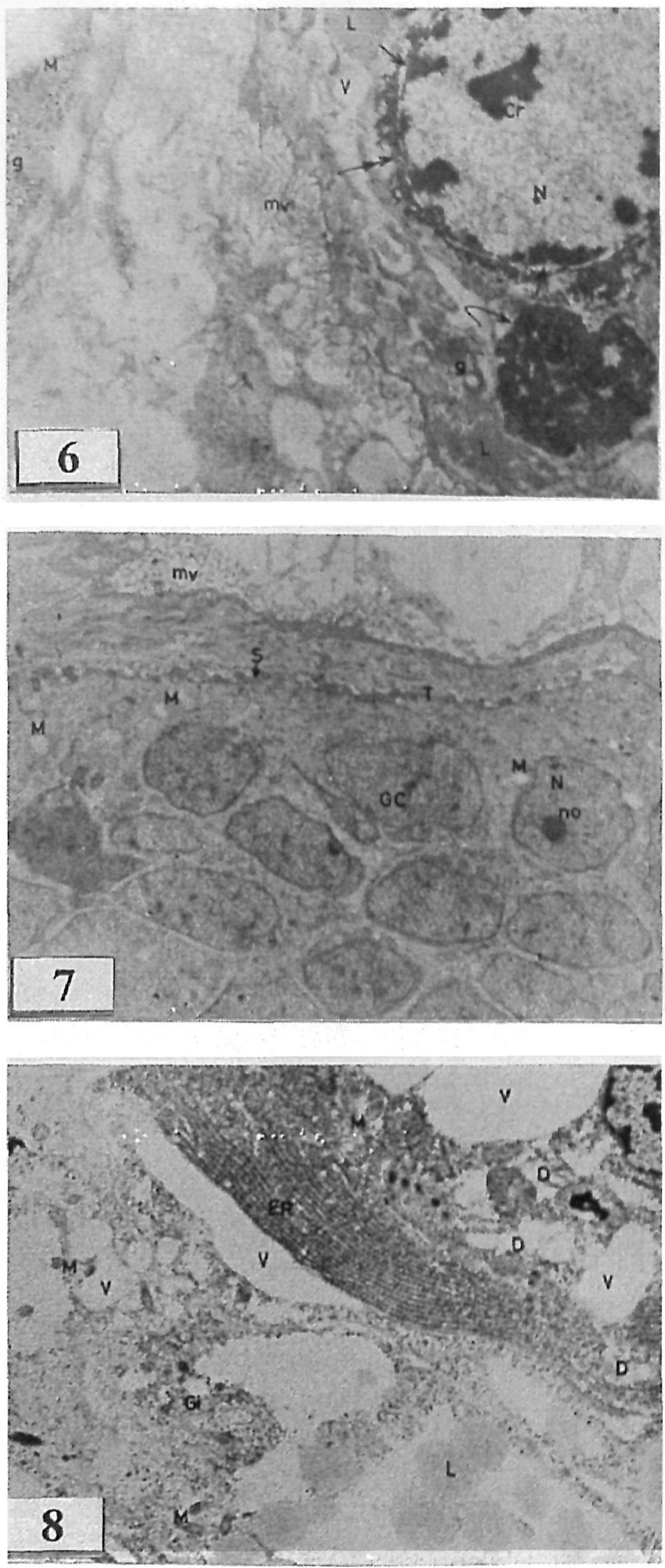


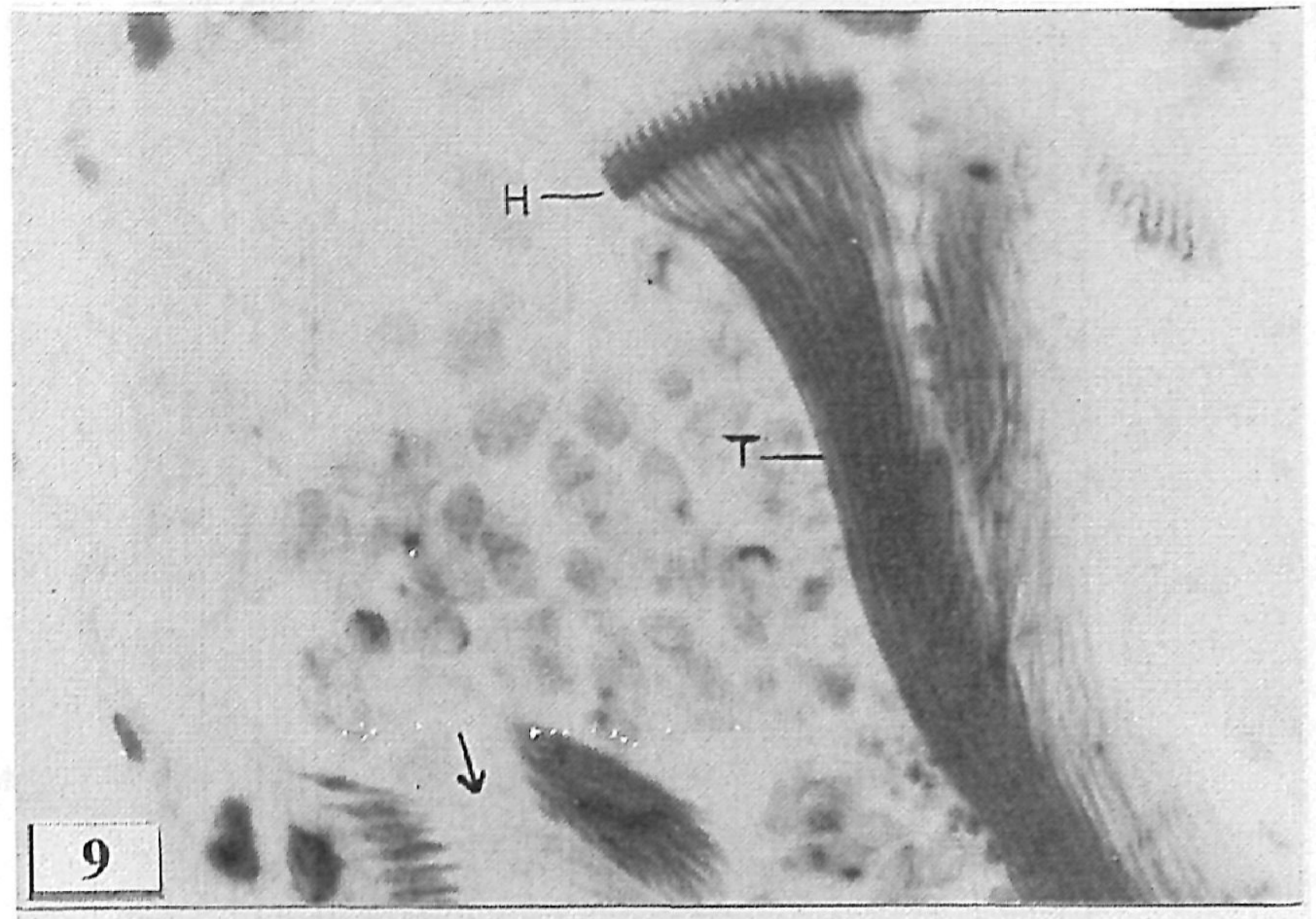

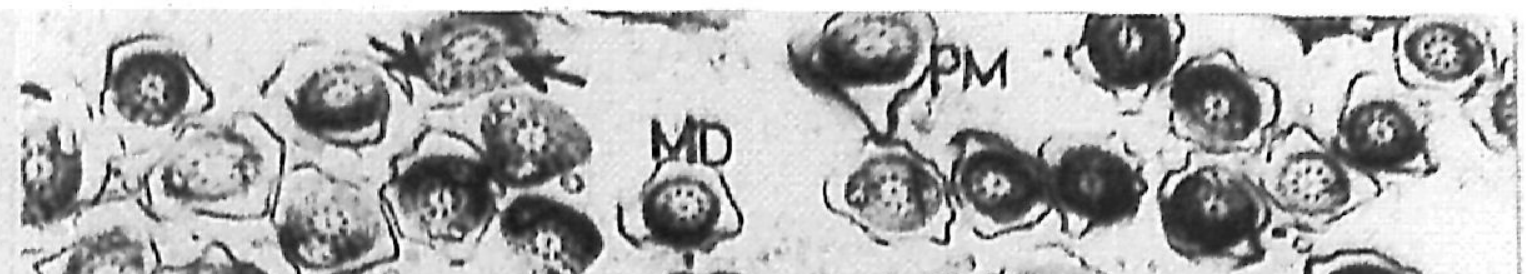

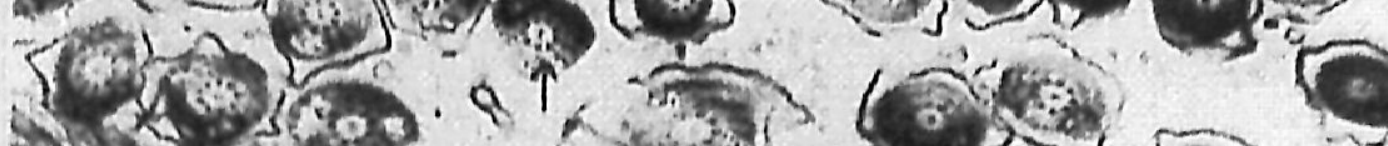

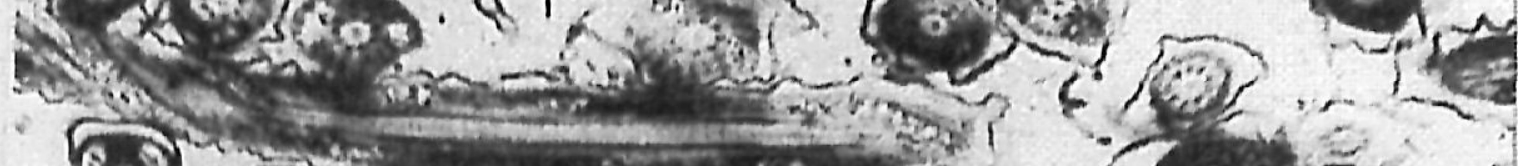

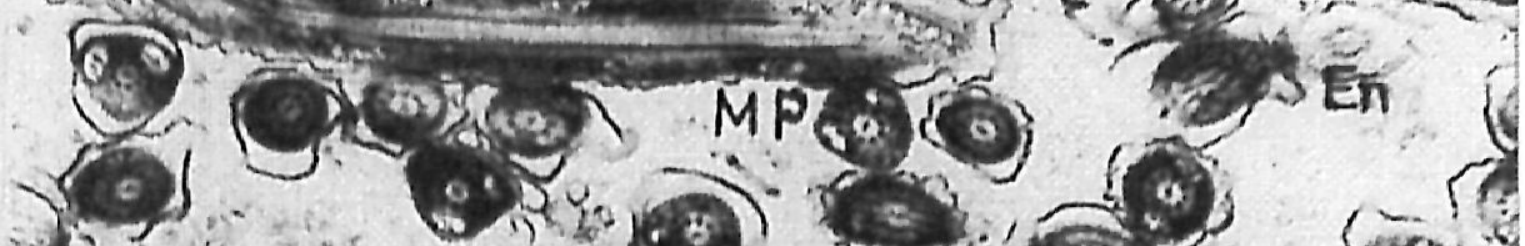

20 क वि की 10 (5) roo

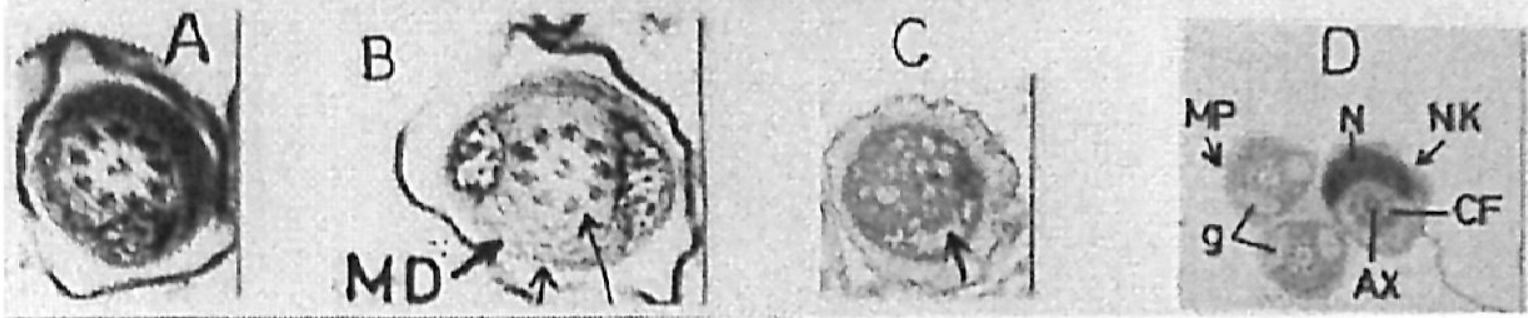



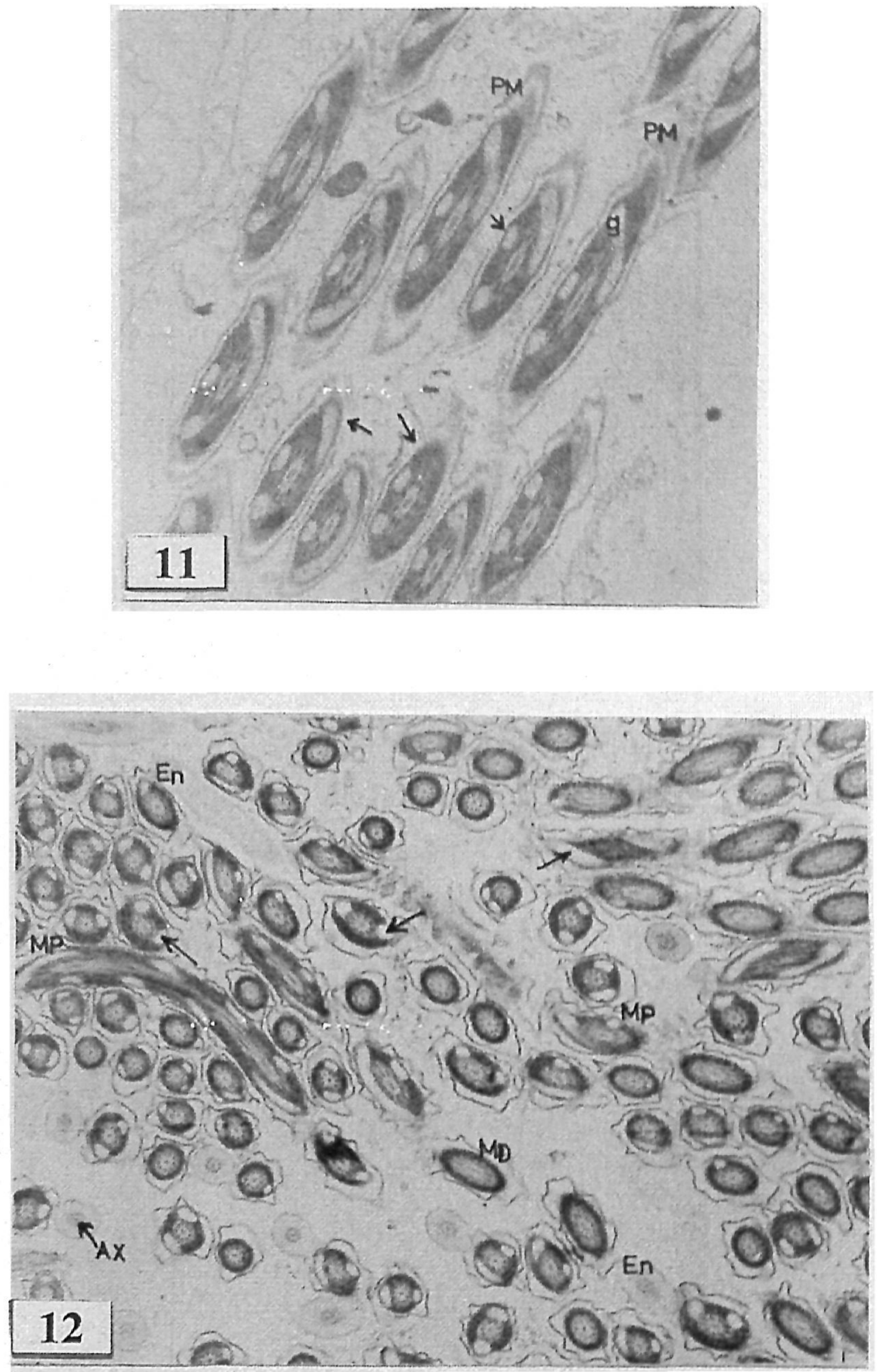

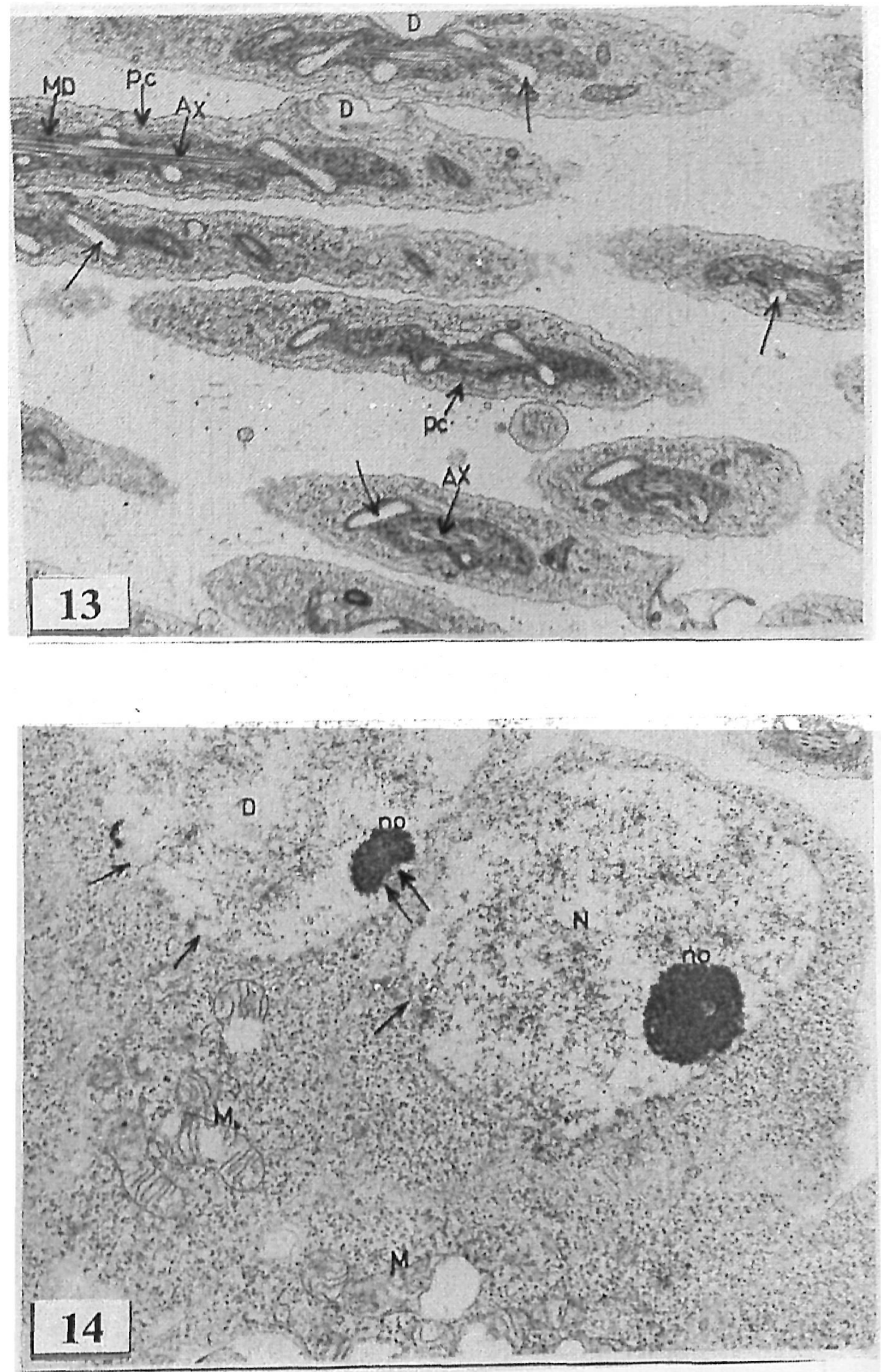


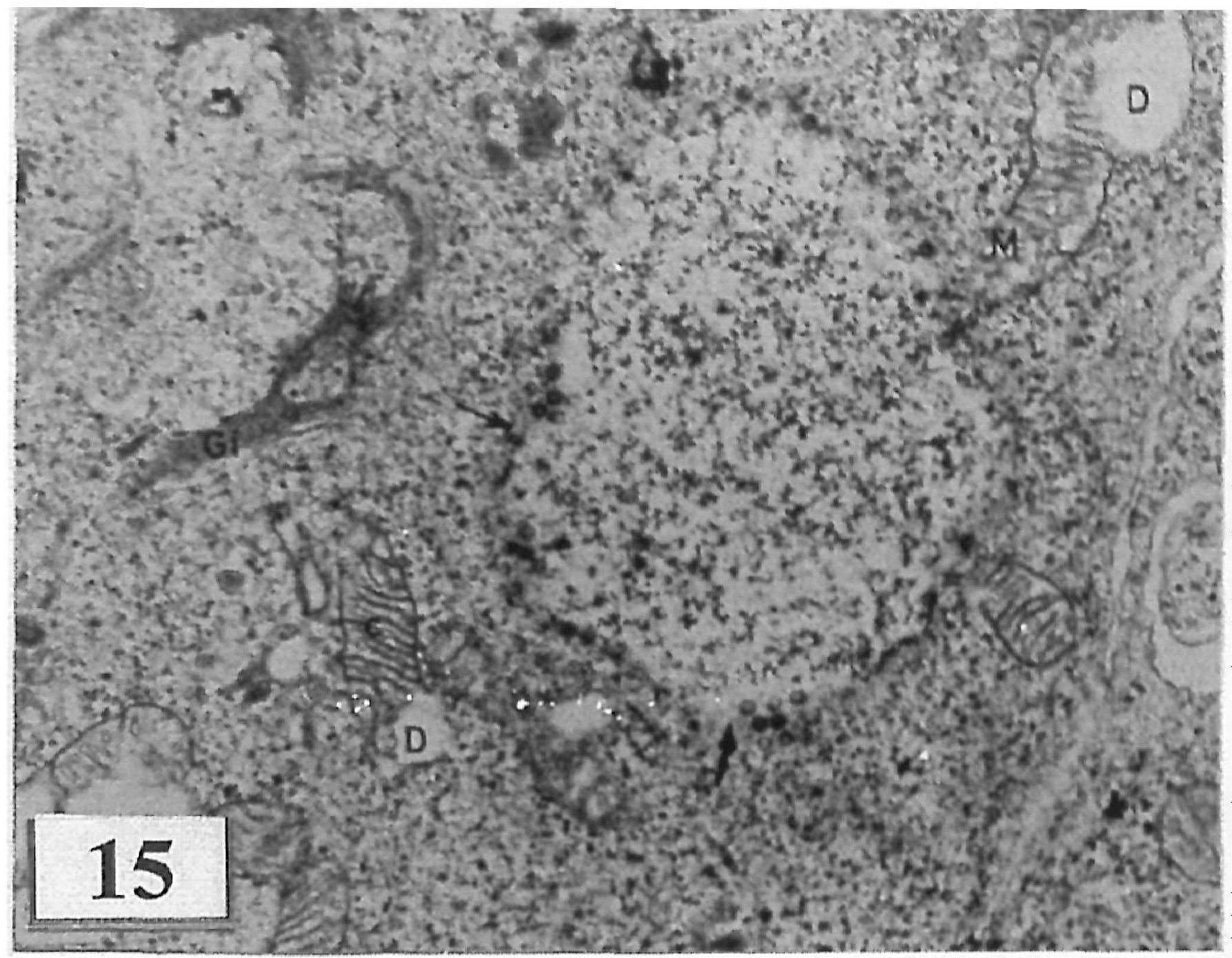

